\title{
Numerical Analysis of Slag Carry-Over during Molten Steel Draining
}

\author{
Daniel Flores-Sanchez, Miguel A. Barron \\ Departmento De Materiales, Universidad Autonoma Metropolitana, Mexico City, Mexico \\ Email:bmma@correo.azc.uam.mx
}

How to cite this paper: Flores-Sanchez, D. and Barron, M.A. (2017) Numerical Analysis of Slag Carry-Over during Molten Steel Draining. Open Journal of Applied Sciences, 7, 611-616.

https://doi.org/10.4236/ojapps.2017.711044

Received: September 27, 2017

Accepted: November 5, 2017

Published: November 8, 2017

Copyright $\odot 2017$ by authors and Scientific Research Publishing Inc. This work is licensed under the Creative Commons Attribution International License (CC BY 4.0).

http://creativecommons.org/licenses/by/4.0/

\begin{abstract}
Slag carry-over during the draining of molten steel from a teeming ladle is numerically studied here. Two-phase isothermal transient 3D Computational Fluid Dynamics simulations were employed to simulate the draining process. Two nozzle diameters, two nozzle positions and three slag heights were considered. From mass balances, the slag carry-over in terms of mass flow rate was obtained for each of the above variables. Besides, the draining times of the teeming ladle were estimated from theoretical considerations and CDF simulations, and compared.
\end{abstract}

\section{Keywords}

CFD Simulations, Draining Time, Multiphase Flow, Slag Carry-Over, Teeming Ladle

\section{Introduction}

Slag carry-over during draining of molten steel from teeming ladles is an important industrial issue given it affects the quality of the solid steel. Main problems of slag carry-over are [1]: 1) hindering of addition of alloys and conditioners; 2) high levels of $\mathrm{FeO}$ and $\mathrm{MnO}$, which result in high oxygen content of steel; 3) increased processing time and treatment costs; 4) high inclusion formation, which causes steel cleanliness problems and increased risk of nozzle clogging during casting; 5) phosphorous reversion in the ladle; 6) poor removal of sulfur in the ladle; and 7) increased ladle refractory wear.

Tapping of molten steel without slag carry-over is a difficult task due to the formation of a draining vortex [2]. In [3] the mechanism of slag carry-over during drainage of metallurgical vessel is studied using a physical model. Vortex and drain sink formation are found to be the main mechanism of carry-over of slag 
to the underlying vessel. The mechanisms of vortex formation are studied in [4] using water modeling and computer simulations. The authors report that the critical bath height for vortex development increases with steel throughputs and nozzle opening.

In this work, the slag carry-over during molten steel draining from a teeming ladle (see Figure 1) is numerically studied using 3D transient isothermal Computational Fluid Dynamics (CFD) simulations. A circular nozzle is located at two positions of the bottom of the ladle: centered and off-centered $(0.5 \mathrm{~m}$ from low border). Two diameters of the nozzles, and three heights of the slag layer are considered. The slag carry-over in terms of mass flow rate of slag is quantified through mass balances as function of nozzle diameter, nozzle position and slag height.

\section{Mathematical Model}

The flow of an isothermal incompressible Newtonian fluid and the mass conservation are represented by the Navier-Stokes equations and the continuity equation,

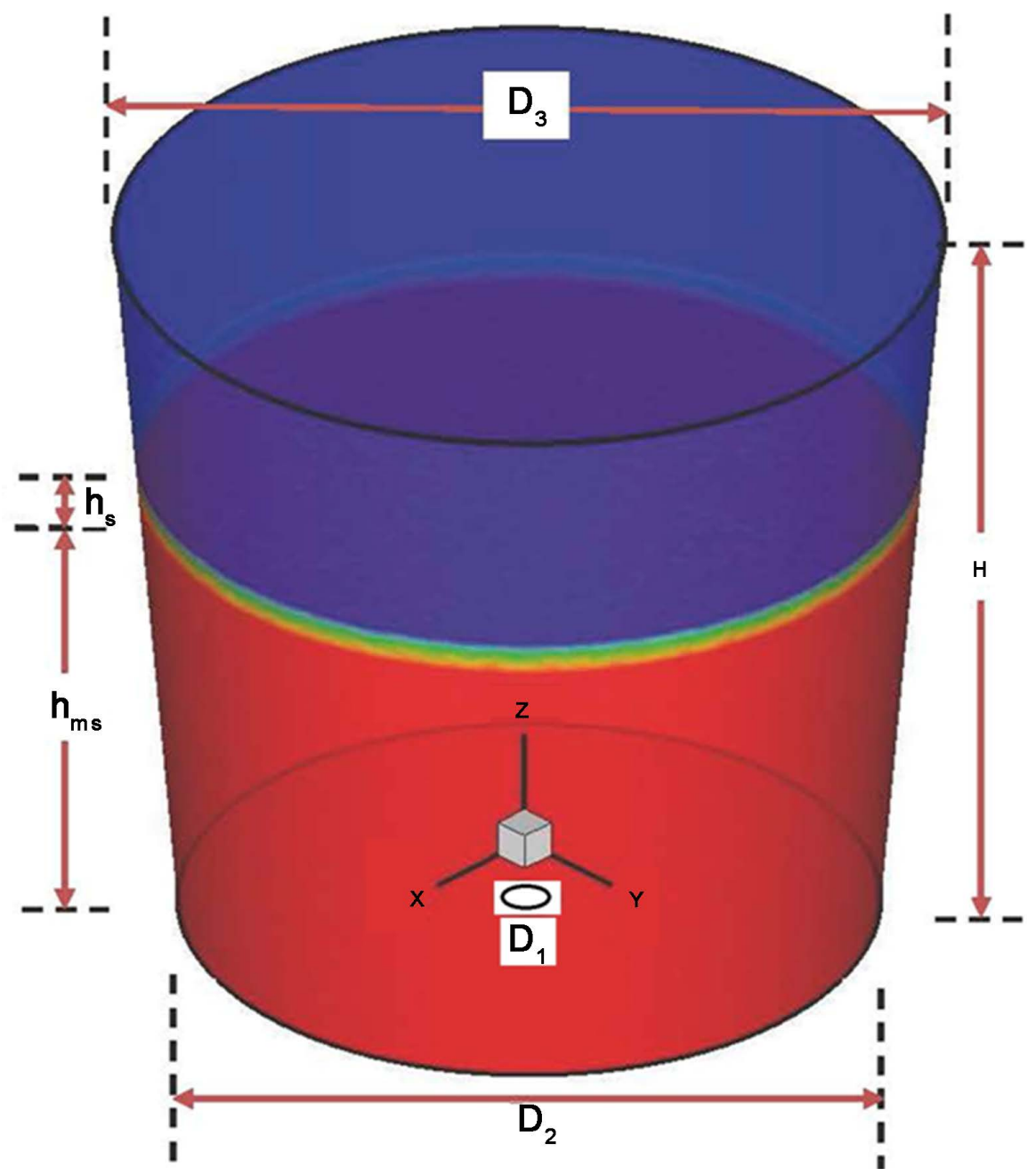

Figure 1. The teeming ladle. In this figure $h_{m s}$ is the height of molten steel and $h_{s}$ is the height of slag. 
respectively [5]. Turbulence in the mold is simulated by means of the classical two equations $\mathrm{K}-\varepsilon$ model [6]. The multiphase nature of the ladle flow is simulated by means of the Volume of Fluid (VOF) model [7], which considers that all the present phases share the same flow field. The mass conservation principle forces that the whole of the phase volume fractions sums the unity.

A mass balance in the teeming ladle yields the following expression, which tracks the time evolution of the molten steel height:

$$
\sqrt{h_{m s}}(t)=\sqrt{h_{m s 0}}-\left(\frac{1}{2}\left(\frac{D_{1}}{D_{2}}\right)^{2} C_{D} \sqrt{2 g}\right) t
$$

where $h_{m s 0}$ is the initial height of molten steel, $C_{D}$ is the nozzle discharge coefficient, $g$ is gravity, and $t$ is time.

On the other hand, the teeming ladle becomes empty when the molten steel height and the slag height become null. In this case, the draining time from Equation (1) is given by:

$$
t_{d}=\frac{2 \sqrt{h_{m s}+h_{s}}}{\left(\frac{D_{1}}{D_{2}}\right)^{2} C_{D} \sqrt{2 g}}
$$

\section{Numerical Simulations}

A cylindrical teeming ladle in which $D_{2}=D_{3}$ (see Figure 1) is considered in the computer simulations. The mesh consists in 250,000 tetrahedral cells. The ladle model is solved using commercial CFD software. Table 1 shows the main parameters of the ladle.

\section{Results and Comments}

Figure 2 and Figure 3 show the slag carry-over corresponding to the $0.05 \mathrm{~m}$ diameter nozzle, in centered and off-centered position, respectively, as function of the slag height. The molten metal height is kept constant at $0.75 \mathrm{~m}$. These Figures show that for both nozzle positions, slag carry-over starts at 1230, 1270

Table 1. Main parameters of the teeming ladle.

\begin{tabular}{ccc}
\hline NAME & SYMBOL & VALUE \\
Ladle diameter & $D_{2}$ & $3.0 \mathrm{~m}$ \\
Nozzle diameter & $D_{1}$ & $0.05,0.1 \mathrm{~m}$ \\
Nozzle discharge coefficient & $C_{D}$ & 1.0 (dimensionless) \\
Initial molten steel height & $h_{m s 0}$ & $0.75 \mathrm{~m}$ \\
Slag height & $h_{s}$ & $0.1,0.15,0.2 \mathrm{~m}$ \\
Molten steel density & $\rho_{\mathrm{ms}}$ & $7100 \mathrm{~kg} \cdot \mathrm{m}^{-3}$ \\
Slag density & $\rho_{\mathrm{s}}$ & $2500 \mathrm{~kg} \cdot \mathrm{m}^{-3}$ \\
\hline
\end{tabular}


and $1295 \mathrm{~s}$ of elapsed time for slag heights of $0.2,0.15$ and $0.10 \mathrm{~m}$, respectively. Besides, for the centered position of the nozzle (Figure 2), the average carry-over for 0.15 and 0.20 slag heights is $4.5 \mathrm{~kg} / \mathrm{s}$, whereas for $0.1 \mathrm{~m}$ of slag height the average carry-over is $4.2 \mathrm{~kg} / \mathrm{s}$. Figure 3 shows that for the $0.05 \mathrm{~m}$ diameter off-centered nozzle the average slag carry-over for 0.1 and $0.5 \mathrm{~m}$ of slag height is around 4.2 $\mathrm{kg} / \mathrm{s}$.

On the other hand, Figure 4 and Figure 5 show the slag carry-over corresponding to the $0.1 \mathrm{~m}$ diameter nozzle, in centered and off-centered position, respectively, as function of the slag height. As in Figure 2 and Figure 3, the molten metal height is maintained constant at $0.75 \mathrm{~m}$. Figure 4 shows that for the centered nozzle position and $0.1 \mathrm{~m}$ of nozzle diameter, slag carry-over starts at 307,312 and $327 \mathrm{~s}$ of elapsed time for slag heights of $0.2,0.15$ and $0.10 \mathrm{~m}$, respectively. For the off-centered position and $0.1 \mathrm{~m}$ nozzle diameter, Figure 5 shows that slag carry-over starts at around 302, 310 and $318 \mathrm{~s}$ of elapsed time for slag heights of $0.2,0.15$ and $0.10 \mathrm{~m}$, respectively. That is, for $0.1 \mathrm{~m}$ of nozzle diameter, slag carry-over starts first for the off-centered nozzle position.

Related to the mass flow rate of slag from the ladle for the $0.1 \mathrm{~m}$ diameter centered nozzle, Figure 4 shows and average of 17.5 and $17.0 \mathrm{~kg} / \mathrm{s}$ for slag heights

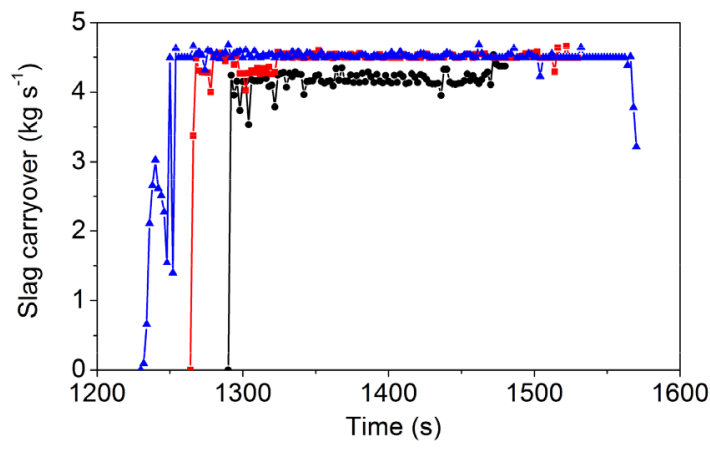

Figure 2. Time evolution of the slag carry-over for three different slag heights: $0.1 \mathrm{~m}$ (black), $0.15 \mathrm{~m}$ (red), $0.2 \mathrm{~m}$ (blue). Nozzle diameter, $0.05 \mathrm{~m}$. Position of the nozzle: centered.

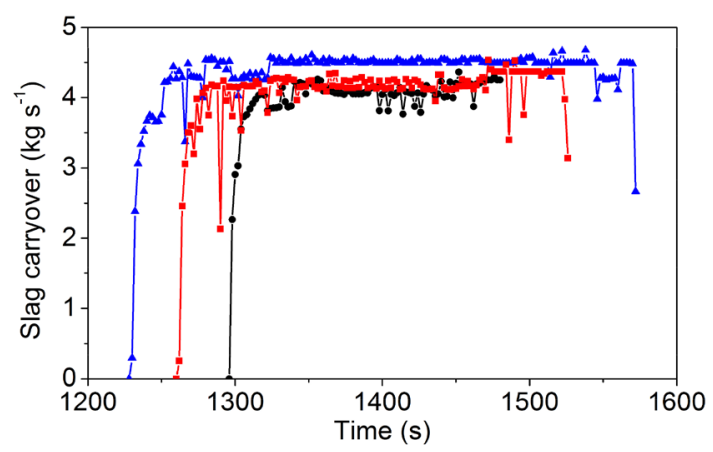

Figure 3. Time evolution of the slag carry-over for three different slag heights: $0.1 \mathrm{~m}$ (black), $0.15 \mathrm{~m}$ (red), $0.2 \mathrm{~m}$ (blue). Nozzle diameter, $0.05 \mathrm{~m}$. Position of the nozzle: off-centered. 


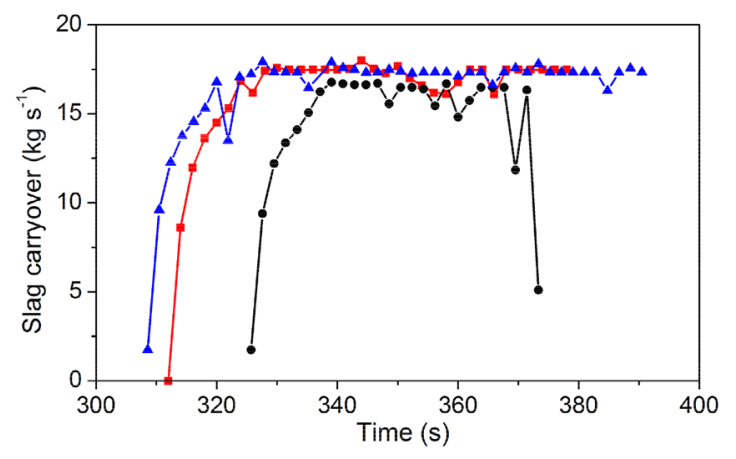

Figure 4. Time evolution of the slag carry-over for three different slag heights: $0.1 \mathrm{~m}$ (black), $0.15 \mathrm{~m}$ (red), $0.2 \mathrm{~m}$ (blue). Nozzle diameter, $0.1 \mathrm{~m}$. Position of the nozzle: centered.

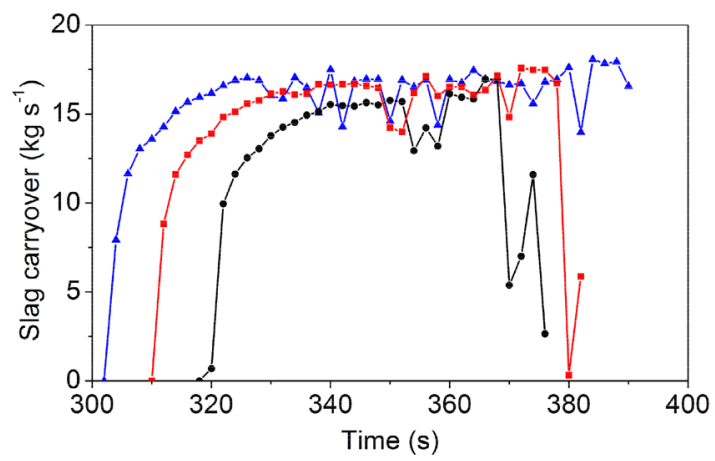

Figure 5. Time evolution of the slag carry-over for three different slag heights: $0.1 \mathrm{~m}$ (black), $0.15 \mathrm{~m}$ (red), $0.2 \mathrm{~m}$ (blue). Nozzle diameter, $0.1 \mathrm{~m}$. Position of the nozzle: off-centered.

Table 2. Draining time for a $0.05 \mathrm{~m}$ diameter nozzle.

\begin{tabular}{cccc}
\hline Slag layer thickness (m) & $\begin{array}{c}\text { Draining time (s), } \\
\text { Equation (2) }\end{array}$ & $\begin{array}{c}\text { Draining time (s) for } \\
\text { centered position, } \\
\text { CFD simulations }\end{array}$ & $\begin{array}{c}\text { Draining time (s) for } \\
\text { off-centered position, } \\
\text { CFD simulations }\end{array}$ \\
\hline 0.10 & 1498.6 & 1470.0 & 1480.0 \\
0.15 & 1542.1 & 1520.0 & 1526.0 \\
0.20 & 1584.3 & 1570.0 & 1570.0 \\
\hline
\end{tabular}

Table 3. Draining time for a $0.10 \mathrm{~m}$ diameter nozzle.

\begin{tabular}{cccc}
\hline Slag layer thickness (m) & $\begin{array}{c}\text { Draining time (s), } \\
\text { Equation (2) }\end{array}$ & $\begin{array}{c}\text { Draining time (s) for } \\
\text { centered position, } \\
\text { CFD simulations }\end{array}$ & $\begin{array}{c}\text { Draining time (s) for } \\
\text { off-centered position, } \\
\text { CFD simulations }\end{array}$ \\
\hline 0.10 & 374.7 & 372.0 & 376.0 \\
0.15 & 385.5 & 378.0 & 382.0 \\
0.20 & 396.1 & 390.0 & 390.0 \\
\hline
\end{tabular}

of $0.15-0.20$ and $0.1 \mathrm{~m}$, respectively. For the $0.1 \mathrm{~m}$ diameter off-centered nozzle, Figure 5 shows and average of 17 and $17.0 \mathrm{~kg} / \mathrm{s}$ for slag heights of $0.15-0.20$ and 
$0.1 \mathrm{~m}$, respectively.

Finally, the draining times were determined from Equation (2) and from CFD computer simulations, considering a molten steel height of $0.75 \mathrm{~m}$ and a nozzle discharge coefficient of 1.0. These draining times are shown in Table 2 and Table 3. It can be observed that the draining times calculated from Equation (2) are slightly larger than those estimated through CFD simulations. This is due to the fact that in CFD simulations some slag is retained in the ladle, whereas Equation (2) considers that the molten steel and the slag are fully drained. Besides, in accordance to CFD simulations, draining time are slightly larger for the off-centered position than that of the centered position.

\section{Conclusions}

The slag carry-over from a teeming ladle was numerically studied. Two nozzle diameters, two nozzle positions and three slag heights were considered in the $3 \mathrm{D}$ transient isothermal CFD computer simulations. The following conclusions arise:

1) Slag carry-over in terms of mass flow rate is significantly increased as the nozzle diameter is increased.

2) Starting time of slag carry-over increases as the slag height decreases.

3) Mass flow rate of slag is slightly larger for the nozzle centered position than that corresponding to the off-centered position.

4) Draining time depends inversely on the nozzle diameter. As the nozzle diameter is increased, the draining time is decreased.

\section{References}

[1] Ametek Land (2017) https://www.landinst.com

[2] Mazumdar, S., Pradhan, N., Bhor, P.K. and Jagannathan, K.P. (1995) Entrainment during Tapping of a Model Converter Using Two Liquid Phases. ISIJ International, 35, 92-94. https://doi.org/10.2355/isijinternational.35.92

[3] Koria, S.C. and Kanth, U. (1994) Model Studies of Slag Carry-Over during Drainage of Metallurgical Vessels. Steel Research, 65, 8-14.

https://doi.org/10.1002/srin.199400919

[4] Morales, R.D., Davila-Maldonado, O., Calderon, I. and Morales-Higa, K. (2013) Physical and Mathematical Models of Vortex Flows during the Last Stages of Steel Draining Operations from a Ladle. ISIJ International, 53, 782-791. https://doi.org/10.2355/isijinternational.53.782

[5] Bird, R.B., Stewart, W.E. and Lightfoot, E.N. (2002) Transport Phenomena. 2nd Edition, Wiley, New York.

[6] Thomas, B.G., Yuan, Q., Sivaramakrishnan, S., Shi, T., Vanka, S.P. and Assar, M.B. (2001) Comparison of Four Methods to Evaluate Fluid Velocities in a Continuous Slab Casting Mold. ISIJ International, 41, 1262-1271. https://doi.org/10.2355/isijinternational.41.1262

[7] Hirt, C.W. and Nichols, B.D. (1981) Volume of Fluid (VOF) Method for the Dynamics of Free Boundaries. Journal of Computational Physics, 39, 201-225. https://doi.org/10.1016/0021-9991(81)90145-5 